\title{
Endoscopic Extraction of CBD Stone: single centre experience in tertiary care centre
}

\author{
Arun Gnawali*, Rahul Pathak, Rajesh Pandey, Prem Krishna Khadga, \\ Sashi Sharma, Anurag Jha, Rabin Hamal, , Dinesh Koirala
}

Department of Gastroenterology and Hepatology, Maharajgunj Medical Campus, TUTH, Institute of Medicine, Kathmandu, Nepal

Keywords: CBD stone, ERCP, Endoscopic sphincterotomy, post-ERCP pancreatitis

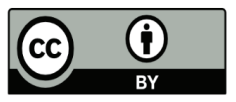

This work is licensed under a Creative Commons Attribution 4.0 Unported License.

\section{Abstract}

Background and Aims: Introduction: Endoscopic Retrograde Cholangiopancreatography(ERCP) has become the first line treatment for patients with common bile duct (CBD) stones. This technique may fail, however, due to presence of a large stone, multiple stones, periampullary diverticula or CBD stricture. The aim of this study was to evaluate the success of CBD cannulation, Endoscopic Sphincterotomy(EST) and CBD clearance in initial attempt, identify the failures of stone extraction and assess the post-ERCP complications.

Methods: A prospective study was carried out over the period of January 2019 to January 2020 on 100 consecutive patients with CBD stones. ERCP was done and the stone size and number recorded. EST was performed using a diathermy unit with a cutting current and stones were extracted using a Balloon catheter or a Dormia basket.

Results: Of the 100 patients, 44 were male and 56 were female with mean age of $52 \pm 17$ years. Selective CBD cannulation and cholangiogram was achieved in $90 \%$, EST was successful in $90 \%$ and complete stone clearance was achieved in first attempt in 46 patients (59\%). 52 patients had difficult CBD stone. There were nine complications, most of which rapidly resolved on conservative treatment (four post-ERCP pancreatitis, three bleeding and one retroperitoneal perforation) and one mortality in an old lady due to PSVT that couldn't be directly attributed to ERCP. Among patients with Stone less than $15 \mathrm{~mm}$ in diameter $(\mathrm{n}=58)$, stone was removed successfully in 45 patients(78\%) whereas in patients with stones over $15 \mathrm{~mm}(\mathrm{n}=20)$ only one was removed successfully (5\%) at initial attempt. Of these 32 patients with residual stones, 13 were referred for surgery and 19 had insertion of biliary stent to be followed by repeat ERCP.

Conclusion: Endoscopic therapy is a simple, effective and safe method of treatment in patients with CBD stone.

\footnotetext{
*Corresponding Author:
}

Dr Arun Gnawali, MBBS, MD

Department of Gastroenterology and Hepatology, Maharajgunj Medical Campus, TUTH, Institute of Medicine, Maharajgunj, Nepal Email: arungnawali969@gmail.com, phone- +977-9845057978 
and stone extraction was first described in $1974^{7}$ and has been a first-line management strategy for choledocholithiasis for the past 3 decades. In diverse settings, including community practice, reported success rates for removing CBD stones at ERCP have commonly ranged from $87 \%$ to $100 \%$, with acceptably low rates of morbidity $(\sim 5 \%){ }^{8,9}$ In approximately $15 \%$ of patients with CBD stones, clearance of the biliary system cannot be obtained using these standard techniques and these kinds of stones are termed as "difficult stones."10 The properties of difficult stones are stone diameter more than $1.5 \mathrm{~cm}$, number of stones $>3$, existence of periampullary diverticula, impacted stone, and biliary stricture. ${ }^{10}$

Recognition and understanding of potential complications of ERCP are vital to accurately assess the clinical appropriateness of ERCP and in the acquisition of appropriate informed consent. Pancreatitis is the most common serious post-ERCP complication. A widely used consensus definition for post-ERCP pancreatitis (PEP) is new or worsened abdominal pain, new or prolongation of hospitalization for at least $48 \mathrm{hrs}$, and serum amylase $\geq 3$ times the upper limit of normal, measured more than 24 hours after the procedure. ${ }^{11}$ By using this definition, the incidence of PEP in a meta-analysis of 21 prospective studies was approximately $3.5 \%{ }^{12}$ but ranges widely(1.6\%-15.7\%). ${ }^{13}$ Hemorrhage is primarily a complication related to sphincterotomy. In a meta-analysis of 21 prospective trials, the rate of hemorrhage was $1.3 \%$ with $70 \%$ of the bleeding episodes classified as mild. ${ }^{12}$ Perforation rates with ERCP range from $0.1 \%$ to $0.6 \% .{ }^{14,15}$

In Nepal, CBD stones are commonly encountered in day to day clinical practice. However, the hospitals which provide ERCP services are mostly confined within the capital city. Therefore, patients from outside Kathmandu are normally referred to centers in Kathmandu. ${ }^{16}$ A prospective observational study was therefore carried to evaluate the success of endoscopic sphincterotomy and complete duct clearance, identify the failures of stone extraction and to note various post-ERCP complications. During the period of this study our policy is to achieve duct clearance at the time of initial hospital admission, otherwise patients will undergo repeat ERCP or additional treatment by surgery or stenting.

\section{Methods:}

100 consecutive patients with CBD stone who either visited OPD or admitted to the TUTH under department of Gastroenterology between January 2019 to January 2020 were considered for the endoscopic therapy. The diagnosis of CBD stone was based on history and imaging on USG or MRCP either depicting CBD stone or in association with dilated common bile duct and obstructive pattern in LFT. All patients had prophylactic antibiotics given with ceftriaxone $1 \mathrm{~g}$ intravenously at the start of the procedure. Topical pharyngeal anesthesia was used (Lignocaine 10\% spray) and intravenous sedation done with Propofol 20 to $100 \mathrm{mg}$ and Duodenal motility was suppressed with intravenous Hyoscine. ERCP was done using side viewing duodenoscope (Pentax ED34-i 10T). Electrosurgical unit (ERBE, Germany,) was used with power setting of $50 \mathrm{~W}$ for both cut and coagulation. All cases were commenced with a standard double lumen sphincterotome preloaded with hydrophilic tip guidewire. Precut with a needleknife papillotome was performed if CBD cannulation was unsuccessful with sphincterotome.

Sphincterotomy was done to its variable length as per the judgement of Gatroenterologist after obtaining cholangiogram. After EST, a CBD stone retrieval was attempted using standard
Balloon or Basket. In cases of failed attempt to remove stones, $\mathrm{CRE}^{\mathrm{TM}}$ balloon dilatation was tried in five patients. The size of $\mathrm{CRE}^{\mathrm{TM}}$ Wire guided balloon was determined by the endoscopist using the diameter of the CBD stones and the degree of tapering of the distal bile duct. The fully inflated $\mathrm{CRE}^{\mathrm{TM}}$ Wire guided balloon was sustained in position for 60 seconds and was then deflated. Mechanical lithotripter was used to break the stone into smaller parts in one patient. Stones were then removed with either Balloon or Basket. In cases where stones could not be removed, plastic stent was placed and the procedure was repeated after few weeks as decided by treating Gastroenterologist. Post procedure patients were kept nil per oral for 4 hours and discharged after 4 hours if no complications occurred during the time. The patients who had complications were admitted in ward. Complications were defined and graded as per the consensus.

The study was approved by the Institutional Review Committee of Institute of Medicine, TUTH. Written informed consent was obtained from all patients prior to enrollment. All intended variables were recorded in preformed performa sheet. Statistical analysis was done using IBM SPSS Statistics version 21.0 software.

\section{Results}

The youngest patient in our study was $22 \mathrm{yrs}$ and oldest of $87 y$ rs including one pregnant lady in 14 weeks of gestation and mean age was $52 \pm 17$ years. Of the 100 patients, 44 were male and 56 were female. The commonest presenting symptom was biliary colic(82\%) followed by obstructive jaundice(55\%) and cholangitis(31\%).

\begin{tabular}{|c|c|}
\hline \multicolumn{2}{|c|}{ Table 1. spectrum of presentation of CBD stone } \\
\hline presentation & No of patients(\%) \\
\hline Biliary colic & 82 \\
\hline Obstructive jaundice & 55 \\
\hline Cholangitis & 31 \\
\hline pruritus & 15 \\
\hline Acute pancreatitis & 11 \\
\hline Incidental detection & 7 \\
\hline
\end{tabular}

80 patient had gallbladder in situ and among them 66 patient(82.5\%) had concomitant GB stone but 20 patient had prior history of cholecystectomy. Majority of our patient were either obese or overweight. 
Chart1: Body mass index of patients

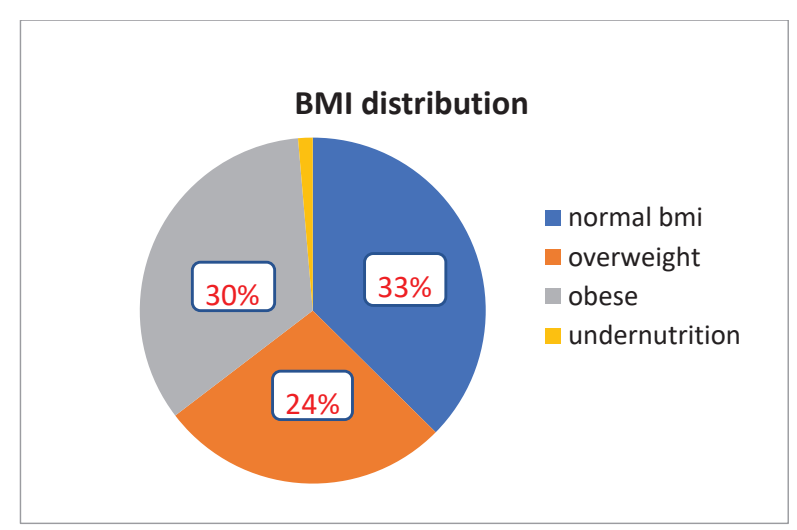

Technically, the selective CBD cannulation was feasible in the 90 patients and among remaining10 patients, 4 had peptic stricture at first part of duodenum and duodenoscope couldn't be negotiated upto second part of duodenum, 3 had difficult anatomy due to prior abdominal surgery and other 3 had large juxtapapillary diverticula which precluded from achieving selective CBD cannulation. Papillary anatomy was observed in 96 patients and 93 had type 1 papilla, 3 had type 2 papilla and none of the patient had type 3 or type 4 papilla. CBD stone was visualized in 78 cases in cholangiogram and 3 had diffusely dilated extrahepatic biliary tree suggestive of type1A choledochal cyst. Endoscopic sphincterotomy was attempted in the 90 patients and was successful in all patients $(90 \%)$. Sphincterotomy was preceded by needle knife papillotomy in 21 cases(24\%). Of the 78patients, complete Duct clearance was achieved in 46 patients(59\%) at the first attemp,19 patient(24\%) underwent CBD stenting with plastic stent to be followed by repeat ERCP and 10 patients(12\%) were referred for surgery due to difficult CBD stone. Stone number was also noted and 39 patient $(50 \%)$ had single stone, 10 patient(13\%) had two stones, 4 patient $(5 \%)$ had three stones and 25 patient $(32 \%)$ had multiple stones $(n \geq 4)$.

As per the stone size, 58 patient $(74 \%)$ had small stones $(<15 \mathrm{~mm})$ and complete duct clearance was achieved in 45 cases(78\%). 20 patient $(26 \%)$ had large stones $(\geq 15 \mathrm{~mm})$ and complete duct clearance was achieved in only one case(5\%). Difficult CBD stone was found in 52 patients(52\%) and most common cause was presence of large stone(38\%) followed by multiple stones(26\%) and impacted stones(25\%).

Chart2: distribution of stone number

\section{Distribution of stone numbers}

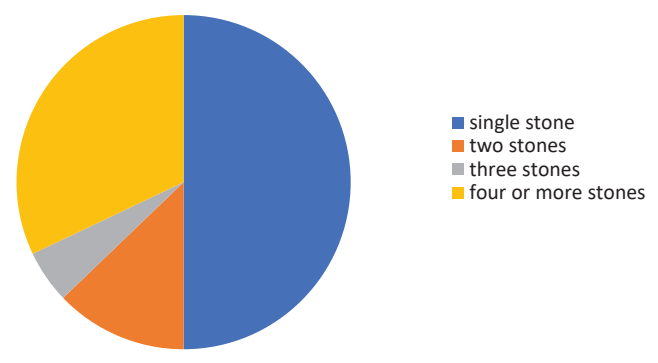

Table 2: causes of difficult CBD stone

\begin{tabular}{|l|r|}
\hline Causes of difficult CBD stone & Number of pts (\%) \\
\hline Large stone $(\geq 15 \mathrm{~mm})$ & $20(38 \%)$ \\
\hline Multiple stones(>3) & $14(26 \%)$ \\
\hline Impacted stone & $13(25 \%)$ \\
\hline Juxtapapillary diverticulum & $8(15 \%)$ \\
\hline hepaticolithiasis & $8(15 \%)$ \\
\hline CBD stricture & $5(10 \%)$ \\
\hline Difficult duodenal anatomy & $3(6 \%)$ \\
\hline Mirizzi syndrome & $1(2 \%)$ \\
\hline
\end{tabular}

CRE dilatation was attempted in 5 patients with multiple CBD stones and was able to achieve complete duct clearance in one patient at first attempt. Another one patient with large stone had complete duct clearance achieved at first attempt by the use of mechanical lithotripter.

Although the cases presented here represent the initial phase of the service in department of Gastroenterology, endoscopic sphincterotomy was found to be remarkably safe procedure. Procedure was uneventful in 91 patients. Four of our patients developed post-ERCP pancreatitis.

Among them 2 had mild self- limiting pancreatitis and other 2 had moderately severe pancreatitis extending the hospital stay by $96 \mathrm{hrs}$ and managed conservatively. Three patients developed bleeding during ERCP but all of them were of mild in nature and neither led to hemodynamic stability nor required blood transfusion and resolved spontaneously. One patient had retroperitoneal perforation managed conservatively within $72 \mathrm{hr}$. There was one mortality in 84yrs lady with history of PSVT and procedure was started with high risk consent. She developed hemodynamic instability post-ERCP due to PSVT and death couldn't be attributed directly to ERCP.

\section{Chart3: post-ERCP complications}

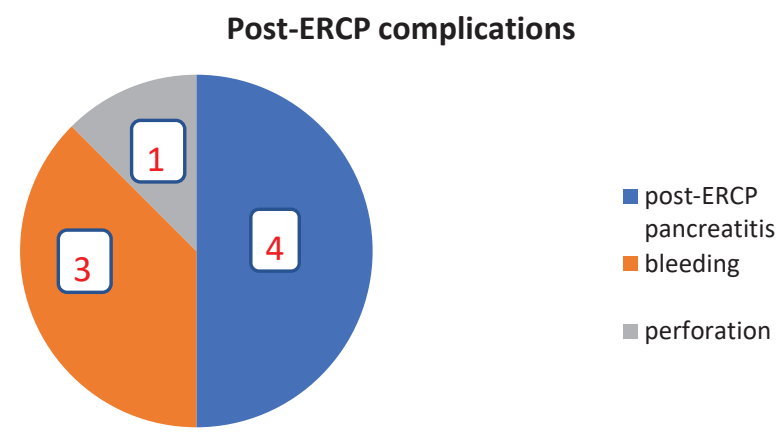

\section{Discussion}

PThe commonest presenting symptom of $\mathrm{CBD}$ stone in our study was biliary colic(82\%) followed by obstructive jaundice(55\%), cholangitis(31\%) and pancreatitis(11\%). In a study by Zargar et al17 in India, commonest presentation was biliary colic(40\%) followed by cholangitis(36\%), acute pancreatitis(12\%) and obstructive jaundice(11\%). Selective CBD cannulation was achieved in $90 \%$ which is comparable with the study done by Gurung et $\mathrm{al}^{16}$ in Dhulikhel hospital( $\left.94.1 \%\right)$. More than one third of the patient $(38 \%)$ had large sized stones (size $\geq 15 \mathrm{~mm}$ ) and findings 
were comparable with the study by Gurung et al16(35.9\%). The significant number of large bile duct stone probably reflects a long standing nature of stone and late detection.16 Complete duct clearance at first attempt could be achieved in 46 patients(59\%) out of 78 patients who had filling defect seen in cholangiogram which is comparable with the study done by Lauri et al 18 where the success of duct clearance during initial attempt was 59\% and in a study by Shrestha et $\mathrm{al}^{19}$, complete stone extraction rate was $41.1 \%$. Another study done by XD Zhou et al20 found that CBD stones were completely cleared during the first procedure session in $46 \%$ patients in the EST group but some other centres reported duct clearance rate of $70-80 \% .^{21,22}$ Allowing a time period after endoscopic sphincterotomy for spontaneous passage of duct stones or biliary stent placement at initial attempt followed by repeat ERCP probably results in higher duct clearance rates. ${ }^{18}$ Other reasons for lower rate of duct clearance in our study could be due to the large stones, multiple stones, impacted stone, hepaticolithiasis and biliary stricture. ${ }^{10}$

Our three patient (3\%) had cholangiogram finding compatible with type 1 A choledochal cyst. Out of 662 patients, Shrestha et a ${ }^{19}$ found choledochal cyst in up to 10 cases (1.64\%) and in $1.2 \%$ of cases in study by Gurung et al. ${ }^{16}$ Prevalence of difficult CBD stone in our study is $52 \%$ which is higher than the prevalence found by $B$ Odemis et al 10 in 1529 patients (13.6\%) and study by McHenry et $\mathrm{al}^{23}$ where it is 10 to $15 \%$. Higher rate of difficult CBD stone in our study could be due to referred cases from other centres including Surgeons due to depiction of hepaticolithiasis or distal CBD stricture in MRCP. Further, $20 \%$ of our patient had prior history of cholecystectomy and that could have altered the anatomy making stone extraction difficult. We referred 13 patients (13\%)for surgery due to difficult CBD stone which is in concordance with the study by Zargar et al17 where the referral rate for surgery was $11.8 \%$.

Among the complications, incidence of post-ERCP pancreatitis was $4 \%$ which is comparable with the study done by Gurung et al 16 in Dhulikhel hospital but none of our patient had severe pancreatitis. Rate of pancreatitis varies between $1 \%$ to $30 \%$ in various academic centers $^{24,25}$ and our rate of pancreatitis is comparable to current literature. Bleeding rate was $3 \%$ in our patients and similar rate was found in the study by Zargar et al. ${ }^{17}$ Retroperitoneal perforation occurred in one patient $(1 \%)$ and Gurung et $\mathrm{al}^{16}$ found perforation rate of $0.2 \%$ in Dhulikhel hospital. None of our patients developed cholangitis immediately after procedure and that could be due to prophylactic antibiotics given in all patients.

There are few limitations in our study. Quality of accessories and lack of mechanical lithotripter and CRE dilator in the initial period of ERCP could have affected the outcome of the procedure. Long term follow up was not done. Further, this study was performed solely under the department of Gastroenterology and small sample size might have contributed to the underestimation of complication rates.

\section{Publication History:}

Date of submission: March 20, 2020

Date of acceptance: May 20, 2020

\section{References}

1. Costi R, Gnocchi A, Di Mario F, Sarli L. Diagnosis and management of choledocholithiasis in the golden age of imaging, endoscopy and laparoscopy. World journal of gastroenterology 2014;20(37):13382-401.

2. Menezes N, Marson LP, debeaux AC, Muir IM, Auld CD.
Prospective analysis of a scoring system to predict choledocholithiasis. The British journal of surgery 2000;87(9):1176-81.

3. Videhult P, Sandblom G, Rasmussen IC. How reliable is intraoperative cholangiography as a method for detecting common bile duct stones? : A prospective populationbased study on 1171 patients. Surg Endosc 2009;23(2):30412.

4. Borzellino G, Rodella L, Saladino E, et al. Treatment for retained [corrected] common bile duct stones during laparoscopic cholecystectomy: the rendezvous technique. Arch Surg 2010;145(12):1145-9.

5. Oria A, Frider B, Alvarez J, et al. Biliary and pancreatic obstruction during gallstone migration. Int J Pancreatol 1988;3(2-3):157-64.

6. Frossard JL, Hadengue A, Amouyal G, et al. Choledocholithiasis: a prospective study of spontaneous common bile duct stone migration. Gastrointest Endosc 2000;51(2):175-9.

7. Demling L, Koch $\mathrm{H}, \mathrm{Classen} \mathrm{M}$, et al. [Endoscopic papillotomy and removal of gall-stones: animal experiments and first clinical results (author's transl)]. Dtsch Med Wochenschr 1974;99(45):2255-7.

8. Cotton PB. Non-operative removal of bile duct stones by duodenoscopic sphincterotomy. Br J Surg 1980;67(1):1-5.

9. Maple JT, Ikenberry SO, Anderson MA, et al. The role of endoscopy in the management of choledocholithiasis. Gastrointestinal Endoscopy 2011;74(4):731-44.

10. \#xd6, demi, \#x15f, et al. Endoscopic Management of the Difficult Bile Duct Stones: A Single Tertiary Center Experience. Gastroenterology Research and Practice 2016;2016:7.

11. Anderson MA, Fisher $L$, Jain $R$, et al. Complications of ERCP. Gastrointestinal Endoscopy 2012;75(3):467-73.

12. Andriulli A, Loperfido $S$, Napolitano $G$, et al. Incidence rates of post-ERCP complications: a systematic survey of prospective studies. Am J Gastroenterol 2007;102(8):17818.

13. Cotton PB, Garrow DA, Gallagher J, Romagnuolo J. Risk factors for complications after ERCP: a multivariate analysis of 11,497 procedures over 12 years. Gastrointest Endosc 2009;70(1):80-8.

14. Freeman ML, Nelson DB, Sherman S, et al. Complications of endoscopic biliary sphincterotomy. N Engl J Med 1996;335(13):909-18.

15. Masci E, Toti G, Mariani A, et al. Complications of diagnostic and therapeutic ERCP: a prospective multicenter study. Am J Gastroenterol 2001;96(2):417-23.

16. Gurung RB, Purbey B, Koju R, BediTR. Endoscopic retrograde cholangiopancreatography at Dhulikhel Hospital: outcome analysis. Kathmandu Univ Med J (KUMJ) 2014;12(45):55-9.

17. Zargar SA, Khan B, Yatloo GN, Gulzar GM. Endoscopic sphincterotomy in the management of the common bile duct stones: Results in 170 patients. JK practitionier 2002;9(1):20-23.

18. Lauri A, Horton RC, Davidson BR, Burroughs AK, Dooley JS. 
Endoscopic extraction of bile duct stones: management related to stone size. Gut 1993;34(12):1718-21.

19. Shrestha R, Shrestha S, Shrestha D. Endoscopic therapy of cholangiopancreatic disease in Bir Hospital, Nepal. Post graduate medical journal of NAMS 2008;8(01).

20. Zhou X-D, Chen Q-F, Zhang $Y-Y$, et al. Outcomes of endoscopic sphincterotomy vs open choledochotomy for common bile duct stones. World journal of gastroenterology 2019;25(4):485-97.

21. Escourrou J, Cordova JA, Lazorthes F, Frexinos J, Ribet A. Early and late complications after endoscopic sphincterotomy for biliary lithiasis with and without the gall bladder 'in situ'. Gut 1984;25(6):598-602.
22. Davidson BR, Neoptolemos JP, Carr-Locke DL. Endoscopic sphincterotomy for common bile duct calculi in patients with gall bladder in situ considered unfit for surgery. Gut 1988;29(1):114-20.

23. McHenry L, Lehman G. Difficult bile duct stones. Current Treatment Options in Gastroenterology 2006;9(2):123-32.

24. Freeman ML, Guda NM. Prevention of post-ERCP pancreatitis: a comprehensive review. Gastrointest Endosc 2004;59(7):845-64.

25. Mallery JS, Baron TH, Dominitz JA, et al. Complications of ERCP. Gastrointest Endosc 2003;57(6):633-8. 